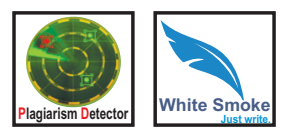

\title{
Combined effect of zinc oxide nano particle incorporated chitosan for better antimicrobial activity towards wound healing
}

\begin{tabular}{lll}
\hline Paper received: 10.05 .2018 & Revised received: 26.10 .2018 & Re-revised received: 11.12 .2018 \\
\hline
\end{tabular}

\section{Authors Info \\ S. Visnuvinayagam ${ }^{1 *}$, L.N. Murthy', A. Jeyakumari', U. Parvathy ${ }^{3}$, R. Anandan ${ }^{4}$, G.K. Sivaraman ${ }^{1}$ and C.N. Ravishankar ${ }^{5}$ ${ }^{1}$ MFB Division, ICAR- CIFT, Cochin-682 029, India \\ ${ }^{2}$ ICAR-Mumbai Research Centre of CIFT, Vashi- 400703 , India \\ ${ }^{3}$ Fish Processing Division, ICAR- CIFT, Cochin-682 029, India ${ }^{4}$ Biochemistry and Nutrition Division, ICAR- CIFT, Cochin-682 029, India ${ }^{5}$ ICAR- CIFT, Cochin-682 029, India}

*Corresponding Author Email : visnuvinayagam@yahoo.co.in

\section{Edited by \\ Dr. Saurabh Chandra}

Reviewed by Professor Rakesh Kumar Dr. Sumati Gaumat

\section{Abstract}

Aim : The aim of the present study was to characterize the zinc oxide nano particle incorporated Chitosan (ZnO-NP-CS) and its antimicrobial activity.

Methodology : Zinc oxide nanoparticles (ZnO-NP) were prepared by sol-gel method and Minimum Inhibitory Concentration (MIC), Minimum bactericidal Concentration (MBC) and agar well diffusion method was used for the assessment of antibacterial activity of ZnO-NP and ZnO-NP-CS as well.

Results : In UV-spectroscopy, blue shift in wavelength $(\sim 365 \mathrm{~nm})$ corresponding to bulk $\mathrm{ZnO}$ particles $(\sim 385 \mathrm{~nm})$ indicates the nano size. In SEM image, $\mathrm{ZnO}-\mathrm{NP}$ appeared as nano flake shape and ZnO-NP treated Methicillin resistant Staphylococcus aureus and Pseudomonas aeruginosa $(\mathrm{PA})$ bacteria illustrates leakage of intracellular content, fusion and shrinkage of bacteria, respectively. The MIC of ZnO-NP for most of food pathogens were between 0.01 to $0.1 \mathrm{mg}$. Lower MIC was observed for Vibrio cholerae and Listeria

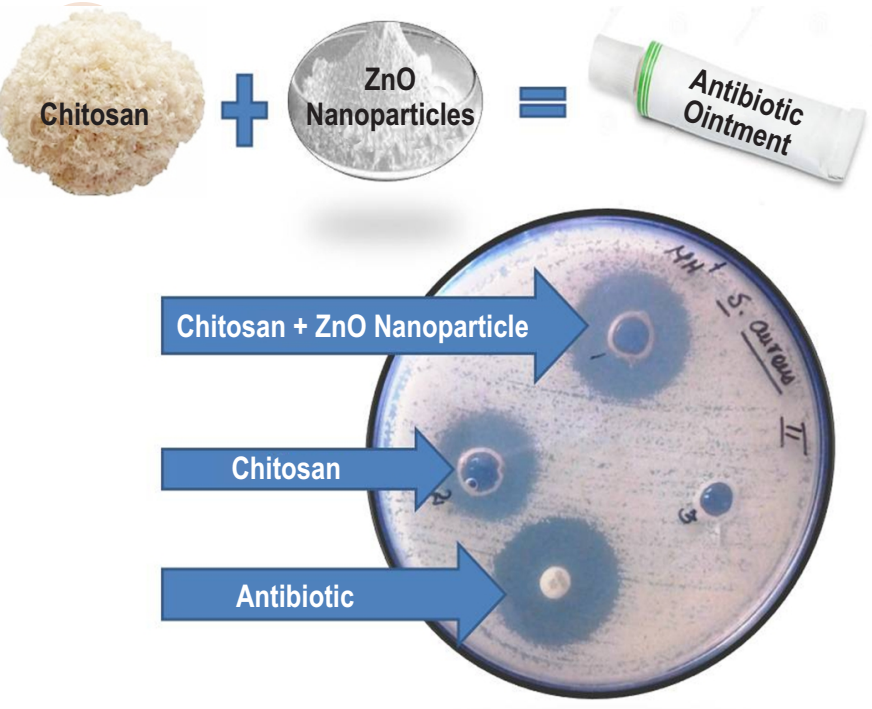
monocytogenes; higher

MIC was observed for Bacillus cereus and Pseudomonas aeruginosa. In antibiogram assay, the zone of inhibition of ZnO-NP-CS was equal to commercial antibiotics against Multiple Drug Resistant bacteria.

Interpretation : The combined effect of ZnO-NP and chitosan is better than the individual component, i.e., around 5-15 mm wider zone of inhibition than chitosan. ZnO-NP-CS can be a suitable alternative for the treatment of wound infected by multiple drug resistant bacteria.

Key words: Antibiogram, Chitosan, MRSA, Zinc oxide nanoparticles

How to cite : S. Visnuvinayagam, L.N. Murthy, A. Jeyakumari, U. Parvathy, R. Anandan, G.K. Sivaraman and C.N. Ravishankar: Combined effect of zinc oxide nano particle incorporated chitosan for better antimicrobial activity towards wound healing. J. Environ. Biol., 40,691-697 (2019). 


\section{Introduction}

Chitosan is a glucosamine polymer commercially obtained by deacetylation of chitin from exoskeletons of crustaceans and a variety of insects, worms, fungi and mushrooms (Muzzarelli et al., 2012). The process of deacetylation (DA) involves removal of acetyl groups from molecular chain of chitin. Activity of chitosan is mainly dependent upon the degree of deacetylation (Baxter et al., 1992). Hence, higher the degree of deacetylation leads to higher antimicrobial activity. Commercially chitosan is available with $>85 \%$ deacetylated units (Goy et al., 2009). Attraction of positively charged chitosan molecules with negatively charged microbial cell membranes leads to disturbance of internal osmotic balances and increased membrane permeability leading to cell death. Even though chitosan possess a broad spectrum of activity; several in vitro experiments indicate that Gram-negative bacteria appear to be more sensitive to chitosan (Goy et al., 2009). Coma et al. (2002) reported that chitosan has higher bacteriostatic effect than bactericidal effect. Commercially, chitosan is being consumed as a drug to reduce the body weight i.e., it is considered as an anti-fat products (Cherniack et al., 2008). Owing to rapid haemostatic active and better healing ability, it is widely used in bandages (Zhang et al., 2010). It is highly efficient to treat defects of joint in bones (Kumar et al., 2017).

Usually Zinc salt are prescribed by medical practitioners for zinc deficient person (Saldamli et al., 1996). Zinc gluconate is famous form of zinc recommended as a supplement for the zinc deficiency. In Ayurveda, metal-based preparations, that is, bhasmas, are indicated for the treatment of several diseases. Standard textbooks of Ayurveda recommend Jasada bhasma (zinc based bhasma) as the treatment of choice for diabetes (Umrani et al., 2014). Reports states that zinc supplement has beneficial effect on type 2 diabetes by elevating the serum leve resulting in better glycemic control. Zinc oxide nano particles (ZnO-NP) also encompass broad spectrum of antibacterial activity similar to chitosan. ZnO-NPs are much more active than its macro size particles (bulk $\mathrm{ZnO}$ ) due to higher surface availability (Sirelkhatim et al., 2015). The properties of ZnO-NP are strongly dependent on structure, morphology, size, orientation and density of crystal. Hence, development of a controllable synthesis of ZnO-NP with specific morphology is important to explore their potential applications and exploitation. Until now, a variety of $\mathrm{ZnO}$ nanostructures such as nano-wires, nano-rods, nano-tubes, nano-belts, nano-flakes and nanoflowers have been synthesized using various techniques such as sol-gel, anodization, sono-chemical, chemical bath deposition, hydrothermal synthesis, gas phase process method and chemical vapor deposition method (Xiong et al., 2014).

Numerous researches have been carried about individual antimicrobial activity of chitosan and $\mathrm{ZnO}-\mathrm{NP}$; but its combined effect has never been studied in such detail. In the present study, zinc oxide Nanoparticle incorporated chitosan (ZnO-NP-CS) was characterized in detail and its antimicrobial activity was estimated for further applications.

\section{Materials and Methods}

Preparation of $\mathrm{ZnO}-\mathrm{NP}$ : ZnO-NPs were prepared as per Sangeetha et al. (2011) with minor modification. One molar zinc nitrate was added drop wise into $1 \mathrm{M} \mathrm{NaOH}$ solution with constant stirring at $70^{\circ} \mathrm{C}$ in equal quantity and kept for $16-24 \mathrm{hrs}$ undisturbed for settlement. Further, the settlement which contained the nanoparticles was centrifuged at $5000 \mathrm{rpm}$ for 5 min and ZnO-NP was washed repeatedly and kept in vacuum oven overnight at $70^{\circ} \mathrm{C}$. This dried $\mathrm{ZnO-NP}$ was further used for characterization studies.

Chitosan: Chitosan (\#GRM 9385, Hi-Media, Mumbai) from shrimp shell with $\geq 75$ deacetylation degree was used in the present study. One percent chitosan was prepared by dissolving in $1 \%$ glacial acetic acid for further biochemical and microbiological analysis.

UV-Visible spectroscopy: ZnO-NP were analyzed using ultraviolet visible (UV-Vis) spectroscopy in the range of 250-700 $\mathrm{nm}$ at room temperature in a quartz cuvette having a path length of $1 \mathrm{~cm}$. Similarly, chitosan and ZnO-NP-CS were analyzed in the range of 200-700nm wave length.

Scanning Electron Microscopy: $16 \mathrm{mM}$ ZnO-NP was directly added into $1 \mathrm{ml}$ of freshly grown MRSA culture and allowed to react for $20 \mathrm{~min}$. The culture was then centrifuged three times at $5000 \mathrm{rpm}$ for $5 \mathrm{~min}$ and pellet was washed with PBS. A $2.5 \%$ of glutaraldehyde in phosphate buffer saline (PBS) was added over the pellets and allowed to react for overnight; then washed with PBS. Finally, to remove water the entire pellet was washed with ascending grade of ethanol, i.e., 20, 40,60, 80 and $100 \%$ and examined in SEM at 2000X to $20000 \mathrm{X}$

Antibiogram: Antibiogram was carried as per $\operatorname{CLSI}(2012,2014)$ standard agar well diffusion technique using Muller Hinton Agar. Test bacterial culture was inoculated into Brain Heart Infusion Broth and incubated at $37^{\circ} \mathrm{C}$ for $2-4 \mathrm{hr}$. The grown cultures were adjusted with sterile normal saline solution until $0.5 \mathrm{McF}$ arland standard turbidity appeared. Sterile cotton swab was immersed into test culture and spread over preset MHA plates, 5-6 mm diameter well was formed using cork borer (\#LA 373, Himedia) and the bottom of agar was sealed with sterile molten agar to avoid leakage. The prepared chitosan $(100 \mu$ l containing $1 \mathrm{mg}$ $\mathrm{ZnO}-\mathrm{NP}$ in $1 \mathrm{mg}$ chitosan) was added to the wells and the plates were incubated at $37^{\circ} \mathrm{C}$. After $24 \mathrm{hr}$, halo zone was measured using standard antibiotic zone scale (PW 096, Hi Media).

Minimum Inhibitory Concentration (MIC) and Minimum Bactericidal Concentration (MBC): MIC for ZnO-NP was carried out using sterile 96 well micro titre plates as per EUCAST (2003). A $100 \mu \mathrm{l}$ of Muller Hinton Broth was added to the wells followed by 100 $\mu \mathrm{mM}$ of ZnO-NP in the first well and mixed firmly. This was followed by serial dilutions ( 2 fold dilution) upto $11^{\text {th }}$ well. Finally, $10 \mu \mathrm{l}$ containing test culture of $3-7 \times 10^{4} \mathrm{CFU}$ was added to all wells in a row, i.e., final concentration of $5 \times 10^{5} \mathrm{CFU} \mathrm{m} \mathrm{l}^{-1}$. After $10-16 \mathrm{hr}$, the 
highest dilution showing no visible growth in 96 well plates was considered as MIC. Similarly, the highest dilution showing no bacterial growth was considered as MBC.

\section{Results and Discussion}

Nanoparticles can destroy bacteria by disturbing the membranes potential and integrity and also by production of reactive oxygen species (ROS). Similarly, chitosan also damage microbial cell membranes by disturbing the internal osmotic balance and by increasing membrane permeability. Since $\mathrm{ZnO}$ NP and chitosan destroy the bacteria by mechanical damage, the possibility of bacteria to develop resistance against chitosan and ZnO-NP is restricted (Beyth et al., 2015). Complete physicochemical characterization of chitosan and ZnO-NP is not possible without using spectroscopic techniques (Kumirska et al., 2010). In this study, the $\lambda_{\max }$ value of ZnO-NP was around $365 \mathrm{~nm}$ (Fig. 1).
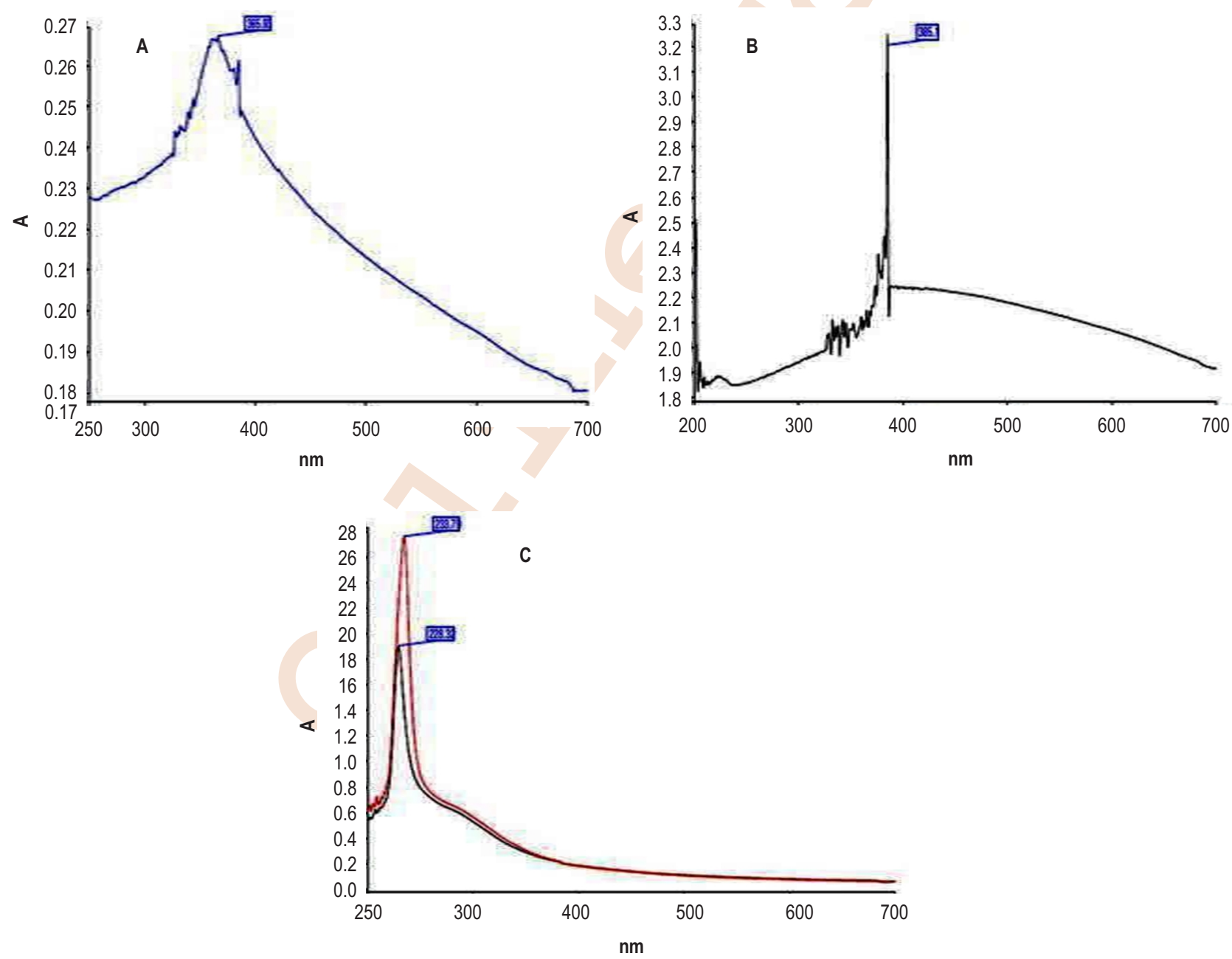

Fig. 1: (A) UV absorption spectra for zinc oxide nano particles; (B) UV absorption spectra for zinc oxide bulk particles; (C) UV absorption spectra for Chitosan and $\mathrm{ZnO} O-N P-C S$.
Similarly, the $\lambda_{\max }$ value for bulk $\mathrm{ZnO}$ particles was around 385 $\mathrm{nm}$ (Fig.1) and $\lambda_{\max }$ for chitosan and ZnO-NP-CS was around $228 \mathrm{~nm}$ and $233 \mathrm{~nm}$ (Fig. 1), respectively. A clear indication of blue shift due to smaller size of nanoparticles was observed. Gupta et al. (2015) and Dobrucka and Dugaszewska (2016) reported that absorption edge systematically shifted to lower wavelength or higher energy with the decreasing size of nanoparticles. Koch et al. (1985) also reported that blue shift in $\mathrm{ZnO}$ nanostructures, comparing with bulk $\mathrm{ZnO}(380 \mathrm{~nm})$ was due to size quantization effect. Similarly, Nawaz et al. (2011) prepared nano and bulk $\mathrm{ZnO}$ particles which exhibited $\lambda_{\max }$ value around 370 and $388 \mathrm{~nm}$, respectively.

As per the studies of Kumirska et al. (2010) and Pedron et al. (2003), UV spectra of mixtures of $\mathrm{N}$-acetyl-glucosamine and glucosamine hydrochloride were quite similar to the spectra of chitosan, and the $\lambda_{\max }$ value was $201 \mathrm{~nm}$ in $0.1 \mathrm{M} \mathrm{HCl}$ solution. In 


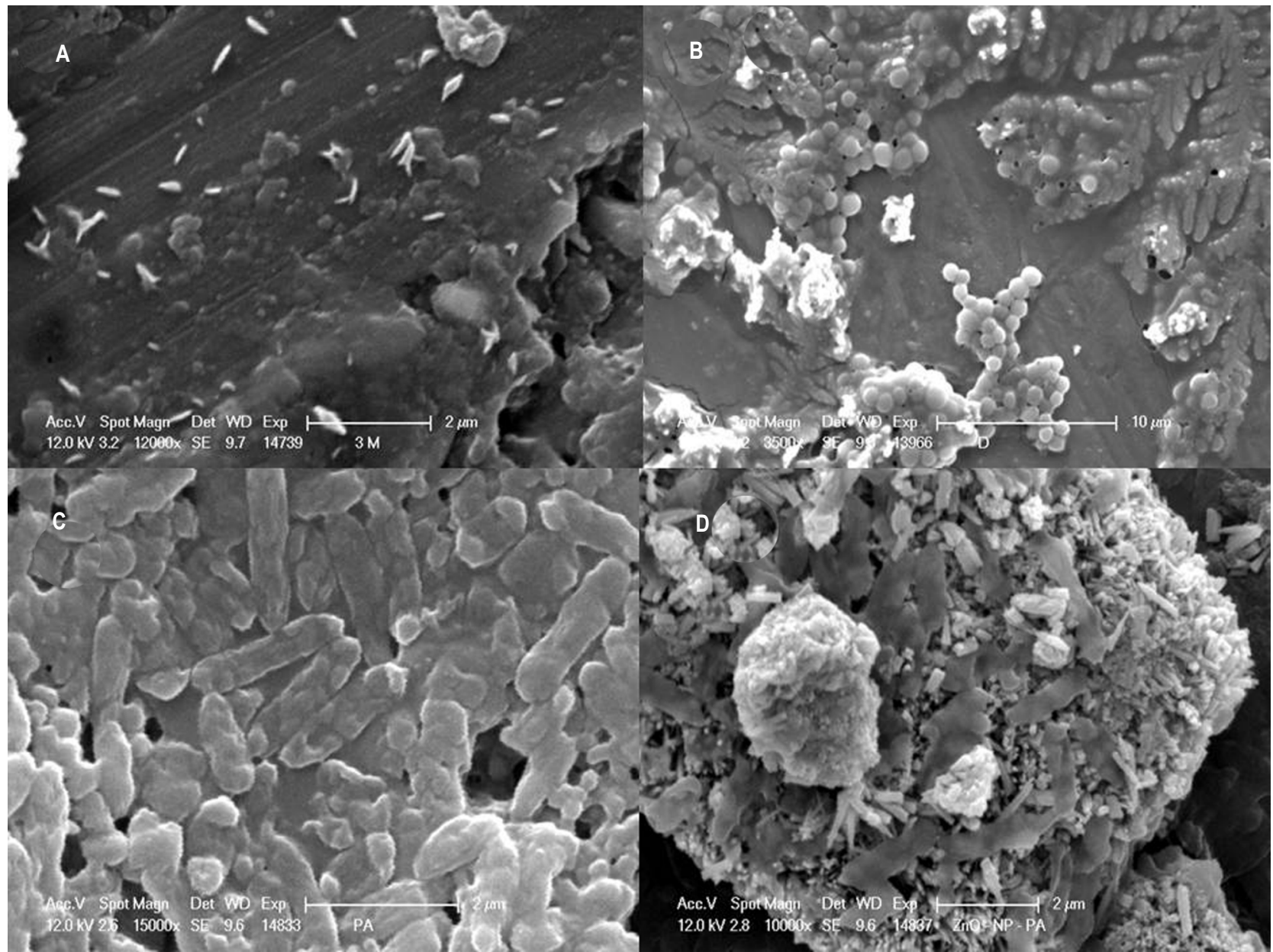

Fig. 2: SEM Images of (A) ZnO-NP; (B) ZnO-NP treated S. aureus; (C) Untreated Pseudomonas aeruginosa and (D) ZnO-NP treated Pseudomonas aeruginosa.

the present study, chitosan was diluted in the acetic acid which might be the reason for $\lambda_{\max }$ being $228 \mathrm{~nm}$ (Fig. 1). Previous studies clearly mention that the structure of nanoparticles (NP), including its morphology, size, orientation and density of the crystal plays a vital role in biological activity (Shinde et al., 2010). Controllable synthesis of $\mathrm{ZnO}$ nanomaterials having specific morphology is important to explore their potential application as smart and functional materials. In SEM analysis, it was found that ZnO-NP was nanoflake (NF) shaped with an average width of 50 $70 \mathrm{~nm}$ and length of $100-200 \mathrm{~nm}$ (Fig. 2). Based on the morphology, it is assumed that the flake size morphology with sharp edges has the ability to penetrate the bacterial surface, ultimately damaging the bacterial cell walls.

Several studies have been conducted to prepare ZnO-NP of varying dimensions. Vabbina et al. (2015) prepared ZnONanoflakes of $20 \mathrm{~nm}$ thickness and average lateral dimensions of $5 \mu \mathrm{m} \times 5 \mu \mathrm{m}$. Lee et al. (2002) synthesized ZnO nano-wire with average length of $13 \mathrm{~mm}$ and typical diameter of $50 \mathrm{~nm}$. Kashif et al. (2012) prepared ZnO nanoflakes of 80-100 nm and a diameter of 300-500 nm. Kaneti et al. (2013) prepared ZnO Nanoflakes with the edge lengths 200 to $400 \mathrm{~nm}$ and thickness ranging from 20 to $35 \mathrm{~nm}$. MRSA is an emerging multidrug resistant bacteria responsible for most skin infection, frequently isolated from the hospitals, humans, animal and fish (Visnuvinayagam et al., 2015; Sivaraman et al., 2017). SEM images of ZnO-NP treated MRSA revealed damage in MRSA membrane along with fusion and shrinkage of cocci (Fig. 2). Similarly, an intra-cellular leakage of the content caused flattening of $P$. aeruginosa (Fig. 2). Scanning electron microscopic studies revealed that the ZnO-NPs were not able to destroy the membrane of $P$. aeruginosa, it may be the reason for the resistance of $P$. aeruginosa against $\mathrm{ZnO}-\mathrm{NP}$, thus leading to higher MIC and MBC values (Table 1). So, based on the SEM analysis, the susceptibility of bacteria against ZnO-NP was assessed. Xie et al. (2011) analyzed the antimicrobial property of $\mathrm{ZnO}-\mathrm{NP}$ with average size of $30 \mathrm{~nm}$ against Campylobacter jejuni 


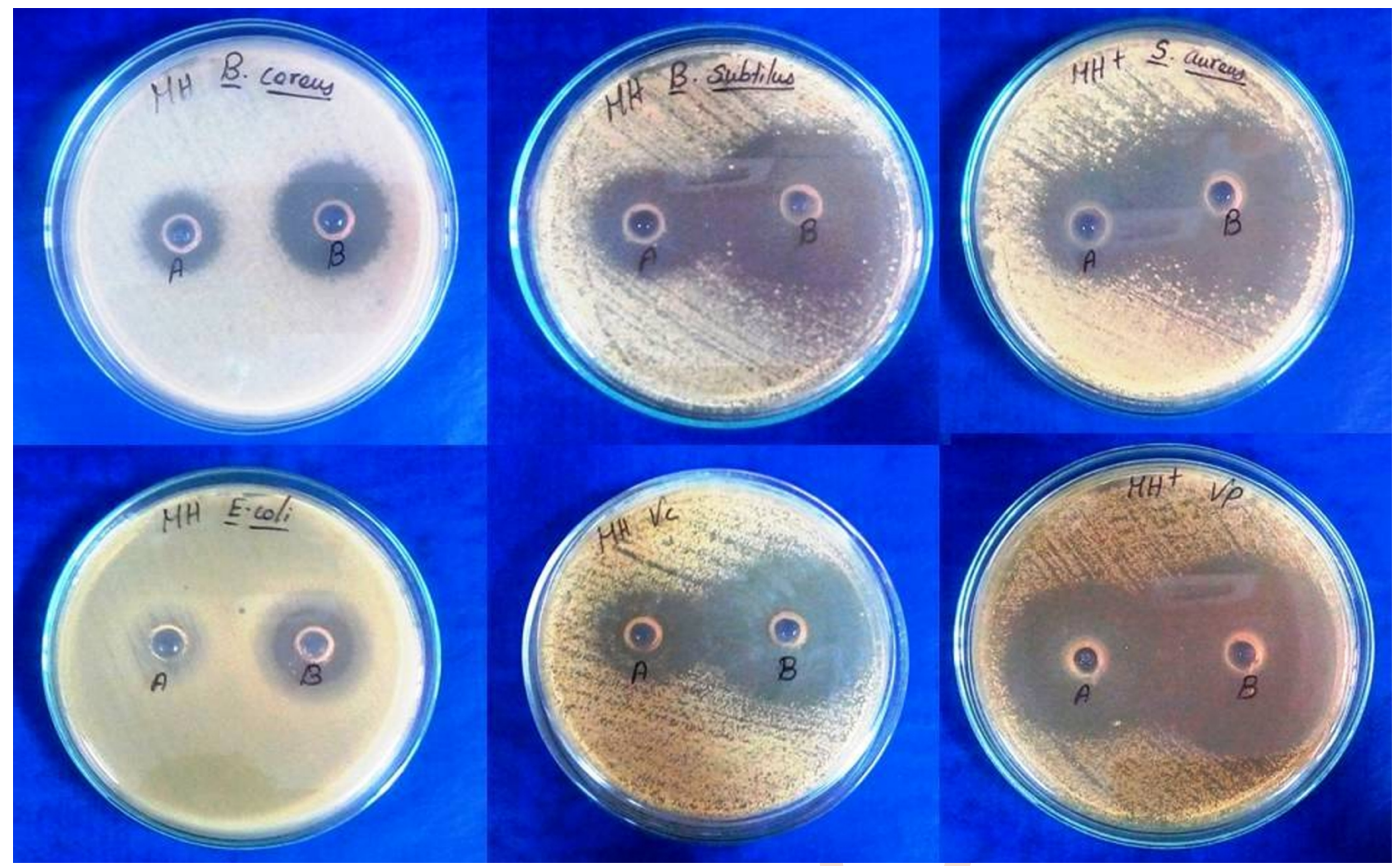

Fig. 3: Antibiogram against food borne pathogens (A) Chitosan and (B) ZnO-NP-CS.

and found that $\mathrm{ZnO}-\mathrm{NP}$ was able to destroy C. jejuniat $0.05 \mathrm{mg} \mathrm{ml}$ ${ }^{1}$, i.e., MIC value was $0.05 \mathrm{mg} \mathrm{ml}^{-1}$. Jones et al. (2008) reported an MIC of $1 \mathrm{mM}$ for ZnO-NP against Staphylococcus aureus. But, in

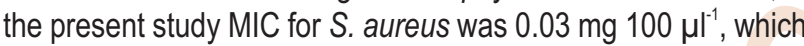
may due to size variation of ZnO-NP. Similarly, Padmavathy and Vijayaraghavan (2008) prepared different size of nanoparticles and proved that nanoparticle sizes were inversely related to the antibacterial activity in terms of both MIC and MBC. In this study, antibiogram was carried out for chitosan alone and compared with nanoparticle incorporated chitosan too. At constant $\mathrm{pH}$ of 3.5, all food borne pathogenic organisms exhibited a zone of inhibition in the range of 5-15 mm, with higher zone size in ZnO-NP-CS compared to chitosan alone (Table 1) (Fig. 3). It clearly indicated that antibacterial activity of chitosan was drastically increased

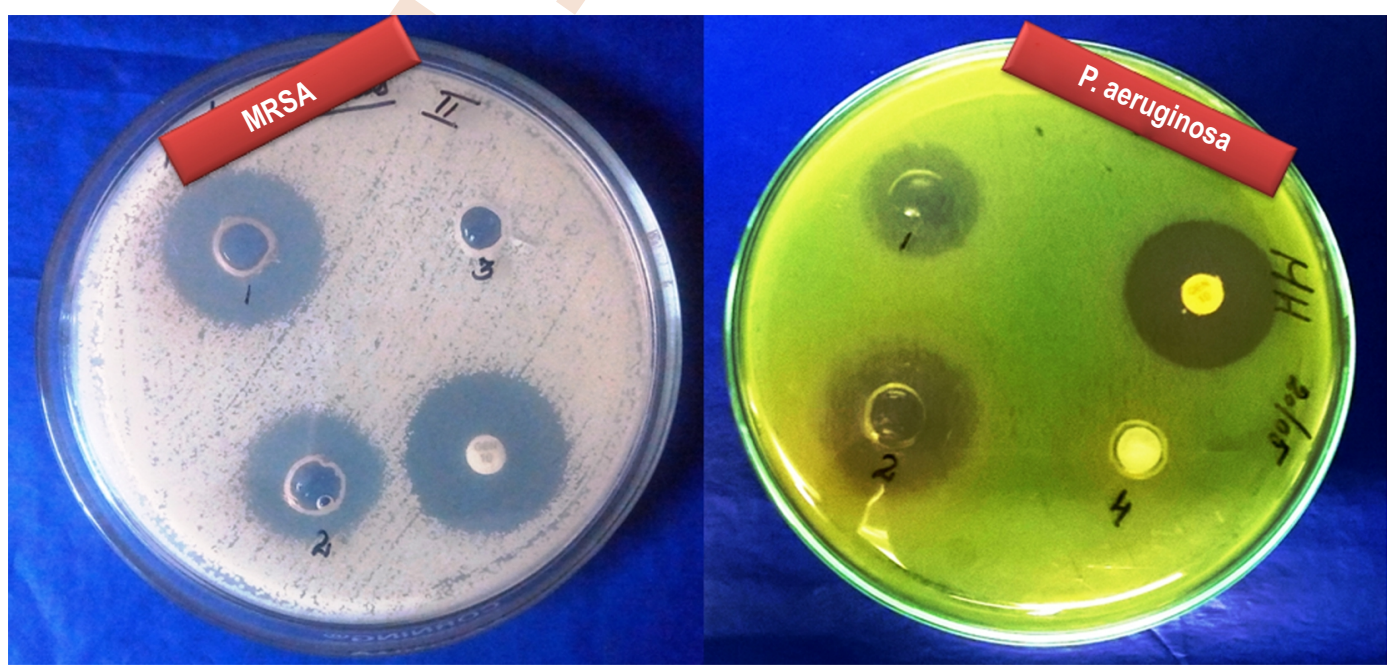

Fig. 4: (A) Antibiogram against MRSA 1. ZnO-NP-CS, 2. Chitosan, 3. ZnO-NP, 4. Gentamicin; (B) Antibiogram against P. aeruginosa 1. Chitosan, 2. ZnO-NP-CS, 3. Gentamicin, 4. ZnO-NP. 
Table 1: MIC and antibiogram result of various food borne and MDR bacteria

\begin{tabular}{llllll}
\hline Bacteria & $\begin{array}{l}\text { MIC } \\
(\mathbf{m g})\end{array}$ & $\begin{array}{l}\text { MBC } \\
(\mathbf{m g})\end{array}$ & $\begin{array}{l}\text { Chitosan zone of } \\
\text { Inhibition }(\mathrm{mm})\end{array}$ & $\begin{array}{l}\text { ZnO-NP-CS zone } \\
\text { of Inhibition }(\mathrm{mm})\end{array}$ & $\begin{array}{l}\text { Difference in zone } \\
\text { of Inhibition }(\mathrm{mm})\end{array}$ \\
\hline $\begin{array}{l}\text { S. aureus } \\
\text { Methicillin Resistant }\end{array}$ & 0.03 & 1.25 & 29 & 40 & 11 \\
Staphylococcus & & & & 13 \\
aureus (MRSA) & 0.06 & 1.25 & 24 & & 14 \\
L. monocytogenes & 0.03 & 0.16 & 22 & 36 & 5 \\
Bacillus cereus & 3.75 & 10.00 & 22 & 29 & 13 \\
B. subtilis & 0.05 & 0.16 & 27 & 40 & 15 \\
Vibrio cholera & 0.01 & 0.23 & 25 & 40 & 5 \\
E. coli & 0.05 & 1.56 & 17 & 22 & 11 \\
Salmonella & 0.10 & 0.94 & 15 & 26 & 12 \\
P. aeruginosa & 15.00 & 20.00 & 21 & 32 & 13 \\
\hline
\end{tabular}

Values are mean of triplicate

after incorporating the $\mathrm{ZnO}$-NP with chitosan. Synergistic effect of ZnO-NP-CS against S. aureus was reported by Sathiya et al. (2018) and they concluded that production of reactive oxygen species (ROS) would be a major reason for antibacterial activity. Similarly, Al-Naamani et al. (2018) reported that higher reduction in bacterial and fungal was observed in ZnO-NP-CS coated package film thus extended the shelf life of Okra (Abelmoschus esculentus) for four more days. It has been reported that chitosan was more active against gram negative bacteria than gram positive bacteria (Goy et al., 2009). But, ZnO-NP-CS was active against both gram negative and gram positive bacteria. Since, the chitosan and its derivatives are being used in various biomedical applications (Martins et al., 2011); ZnO-NP-CS can be applied for improved activity antimicrobial and healing purpose. In the present study, more emphasis was given to the $\mathrm{ZnO}-N P-C S$ as an ointment against pathogenic bacteria causing delayed wound healing.

Antibiogram was also carried out against multiple drug resistant bacteria viz., MRSA and Pseudomonas aeruginosa, which are responsible for various major surface wound infections. In antibiogram against MDR bacteria, ZnO-NP-CS zone of inhibition was found to be equal to commercial antibiotics (Fig. 4). Hence, $100 \mu \mathrm{l}$ of ZnO-NP-CS (1 mg of ZnO$\mathrm{NP}$ in $1 \mathrm{mg}$ of chitosan) was found equally effective to commercial antibiotics (10 $\mathrm{mg}$ of Gentamicin). The present study has revealed the suitability of zinc oxide nano particle incorporated chitosan (ZnO-NP-CS) as an effective alternative to commercial antibiotics for treatment of wound infections affected by multiple drug resistant bacteria.

\section{Acknowledgment}

The microbiological work carried out by Mrs. Sangeetha Murthy, Mumbai Research Centre of Central Institute of Fisheries Technology is thankfully acknowledged.

\section{References}

Al-Naamani, L., J. Dutta and S. Dobretsov: Nanocomposite zinc oxidechitosan coatings on polyethylene films for extending storage life of okra (Abelmoschus esculentus). Nanomaterials, 8, 479-494 (2018).

Baxter, A., M. Dillon, K.D.A. Taylor and G.A.F. Roberts: Improved method for I.R. determination of the degree of $\mathrm{N}$-acetylation of chitosan. Int. J. Biol. Macromol., 14, 166-169(1992).

Beyth, N., Y. Houri-Haddad, A. Domb, W. Khan and R. Hazan: Alternative antimicrobial approach: Nano-antimicrobial materials. EvidenceBased Complem. Alte. Medi., 2015 (2015). http://dx. doi. org/10.1155/2015/246012.

Cherniack, E.P.: Potential applications for alternative medicine to treat obesity in an aging population. Altern. Medi. Revi., 13, 34-40 (2008).

CLSI: Clinical and Laboratory Standards Institute Performance Standards for Antimicrobial Susceptibility Testing; Twenty-Fourth Informational Supplement. CLSI document M100-S24, Wayne (2014).

CLSI: Clinical and Laboratory Standards Institute Methods for Dilution Antimicrobial Susceptibility Tests for Bacteria That Grow Aerobically; Approved Standard-Ninth Edition. CLSI document M07-A9. Wayne (2012)

Dobrucka, R. and J. Dlugaszewsk: Biosynthesis and antibacterial activity of $\mathrm{ZnO}$ nanoparticles using Trifolium pratense flower extract. Saudi J. Biol. Sci., 23, 517-523 (2016).

EUCAST: European Committee for Antimicrobial Susceptibility Testing (EUCAST) of the European Society for Clinical Microbiology and Infectious Diseases (ESCMID). EUCAST Discussion DocumentE. Dis 5.1: determination of minimum inhibitory concentrations (MICs) of antibacterial agents by broth dilution. Clin. Microbiol. Infec., 9, 1-7 (2003).

Goy, R. C., D. D. Britto and O. B. Assis: A review of the antimicrobial activity of chitosan. Polímeros, 19, 241-247 (2009).

Gupta, A., P. Srivastava, L. Bahadur, D. P. Amalnerkar and R. Chauhan: Comparison of physical and electrochemical properties of $\mathrm{ZnO}$ prepared via different surfactant-assisted precipitation routes. Appl. Nanosci., 5, 787-794 (2015).

Jones, N., B. Ray, K.T. Ranjit and A. Manna: Antibacterial activity of ZnO 
nanoparticle suspensions on a broad spectrum of microorganisms. FEMS Microbiol. Letters, 279, 71-76 (2008).

Kaneti, Y. V., J. Yue, X. Jiang and A. Yu: Controllable synthesis of ZnO nanoflakes with exposed (1010) for enhanced gas sensing performance. J. Physi. Chemi., C, 117, 13153-13162 (2013).

Kashif, M., U. Ali, M. Syed, M.E. Ali, H.I. Abdulgafour, U. Hashim, M. Willander and Z. Hassan: Morphological, optical and Raman characteristics of $\mathrm{ZnO}$ nanoflakes prepared via a sol-gel method. Physica Status Solidi (a), 209, 143-147 (2012).

Koch, U., A. Fojtik, H. Weller and A. Henglein: Photochemistry of semiconductor colloids. Preparation of extremely small $\mathrm{ZnO}$ particles, fluorescence phenomena and size quantization effects. Chemical Physics Letters, 122, 507-510 (1985).

Kumar, B.N.P., S. Mahaboobi and S. Satyam: Chitosan in Medicine-A Mini Review. J. Mol. Pharm. Org. Process Res., 5, 2-6 (2017).

Kumirska, J., M. Czerwicka, Z. Kaczyński, A. Bychowska, K. Brzozowski, J. Thöming and P. Stepnowski: Application of spectroscopic methods for structural analysis of chitin and chitosan. Marine Drugs, 8, 1567-1636 (2010).

Lee, C. J., T. J. Lee, S.C. Lyu, Y. Zhang, H. Ruh and H.J. Lee: Field emission from well-aligned zinc oxide nanowires grown at low temperature. Applied Physics Letters, 81, 3648-3650 (2002).

Martins, A. F., A.G. Pereira, A.R. Fajardo, A.F. Rubira and E.C. Muniz: Characterization of polyelectrolytes complexes based on $\mathrm{N}, \mathrm{N}, \mathrm{N}-$ trimethyl chitosan/heparin prepared at different $\mathrm{pH}$ conditions. Carbohydrate Polymers, 86, 1266-1272 (2011).

Muzzarelli, R.A.A., J. Boudrant, D. Meyer, N. Manno, M. DeMarchis and M.G. Paoletti: Current views on fungal chitin/chitosan, human chitinases, food preservation, glucans, pectins and inulin: A tribute to Henri Braconnot, precursor of the carbohydrate polymers science on the chitin bicentennial. Carbohydrate Polymers, 87 995-1012 (2012).

Nawaz, H. R., B. A. Solangi, B. Zehra and U. Nadeem: Preparation of nano zinc oxide and its application in leather as a retanning and antibacterial agent. Canadian J. Sci. Indus. Res, 2, 164-170 (2011).

Padmavathy, N. and R. Vijayaraghavan: Enhanced bioactivity of ZnO nanoparticles-An antimicrobial study. Sci. Technol. Adv. Mate., 9 p. 035004-035008 (2008).

Pedroni, V. I., M.E. Gschaider and P. Schulz: UV spectrophotometry: Improvements in the study of the degree of acetylation of chitosan. Macromole. Biosci., 3, 531-534 (2003).

Saldamli, I., H. Koksel, O. Ozboy, I. Ozalp and I. Kilic: Zincsupplemented bread and its utilization in zinc deficiency. Cereal
Chem. .73, 424-427 (1996).

Sangeetha, G.S. Rajeshwari and R. Venckatesh: Green synthesis of zinc oxide nanoparticles by Aloe barbadensis miller leaf extract: Structure and optical properties. Mate. Res. Bull., 46, 2560-2566 (2011).

Sathiya, S.M., G.S.Okram, S.M.Dhivya, S Mugesh, M. Murugan and M.A. Rajan: Synergistic bactericidal effect of chitosan/zinc oxide based nanocomposites against Staphylococcus aureus. Advan. Sci. Lett., 24, 5537-5542 (2018)

Shinde, V. R., T.P. Gujar, T. Noda, D. Fujita, A. Vinu, M. Grandcolas and J. Ye: Growth of shapeDand size $\square$ selective zinc oxide nanorods by a microwave $D a s s i s t e d$ chemical bath deposition Method: Effect on photocatalysis properties. Chemistry-A European J., 16, 1056910575 (2010).

Sirelkhatim, A., S. Mahmud, A. Seeni, N.H.M. Kaus, L.C. Ann, S.K.M. Bakhori, H. Hasan and D. Mohamad: Review on zinc oxide nanoparticles: Antibacterial activity and toxicity mechanism. NanoMicro. Letters, 7, 219-242 (2015).

Sivaraman, G. K., S. Vishnuvinayagam, A.K. Jha, V. Renuka, S. Remya and D. Vanik: Assessment of microbial quality of fish processing industrial effluent in bar-mouth at Bhidia landing site, Veraval, Gujarat, India. J. Environ. Biol., 37, 537-541(2017).

Umrani, R.D. and K.M. Paknikar: Zinc oxide nanoparticles show antidiabetic activity in streptozotocin-induced Type 1 and 2 diabetic rats. Nanomedicine, 9, 89-104 (2014).

Vabbina, P. K., A. Kaushik, N. Pokhrel, S. Bhansali and N. Pala: Electrochemical cortisol immunosensors based on sonochemically synthesized zinc oxide $1 \mathrm{D}$ nanorods and $2 \mathrm{D}$ nanoflakes. Biosen. Bioelectro., 63, 124-130 (2015).

Visnuvinayagam, S., T.C. Joseph, V. Murugadas, R. Chakrabarti and K.V. Lalitha: Status on methicillin resistant and multiple drug resistant Staphylococcus aureus in fishes of Cochin and Mumbai coast, India. J. Environ. Biol. 36, 571-575(2015).

Xie, Y., Y. He, P.L. Irwin, T. Jin and X. Shi: Antibacterial activity and mechanism of action of zinc oxide nanoparticles against Campylobacter jejuni. Appli. Enviro. Microbiol., 77, 2325-2331 (2011).

Xiong, G., H. Luo, J. Zhang, J. Jin and Y. Wan: Synthesis of ZnO by chemical bath deposition in the presence of bacterial cellulose. Acta Metallurgica Sinica (English Letters), 27, 656-662 (2014).

Zhang, J., W. Xia, P. Liu, Q. Cheng, T. Tahi, W. Gu and B. Li: Chitosan modification and pharmaceutical/biomedical applications. Marine Drugs, 8, 1962-1987 (2010). 